\title{
Genitourinary malignancy presenting as an ocular metastasis: A case report and review of the literature
}

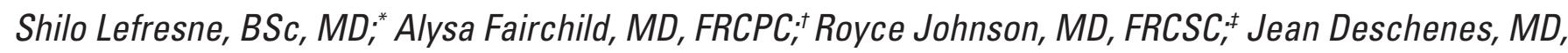 \\ FRCPC,; Laurie Russell, MD, FRCPC, ${ }^{ \pm}$John Pederson, MD, FRCPC ${ }^{+}$
} `Department of Radiation Oncology, BC Cancer Agency, Vancouver, BC; †Department of Radiation Oncology, Cross Cancer Institute, Edmonton, AB; ;Department of Ophthalmology, University of Alberta,
Edmonton, AB; \$Pathology Department, Cross Cancer Institute, Edmonton, AB; *University of Alberta Hospital, Edmonton, AB

Cite as: Can Urol Assoc J 2012;6(2):e67-71. http://dx.doi.org/10.5489/cuaj.10174

\begin{abstract}
Metastases to the eye or orbit as the initial presentation of genitourinary malignancy are unusual and can be a diagnostic challenge. We report an 81-year-old man who presented with pain and proptosis in an eye that had been blind for 50 years. Radiologic investigations identified a mass involving the left globe and orbit. Histology of the enucleation specimen was consistent with a metastatic poorly differentiated carcinoma suggestive of a prostate primary. With the constellation of obstructive urinary symptoms, an abnormal digital rectal examination, elevated prostate-specific antigen and a positive bone scan, androgen deprivation therapy was initiated for metastatic prostate cancer. After an initial response to treatment, the patient's disease progressed in a manner atypical for prostate cancer. After describing our case, we review the literature on ocular and orbital metastases and their relation to genitourinary malignancies.
\end{abstract}

\section{Introduction}

Between $2 \%$ and $5 \%$ of cancer patients will develop an ocular or orbital metastasis. In $25 \%$ of these, it is the presenting sign of malignancy. ${ }^{1-4}$ Frequently, this presents a diagnostic challenge and represents a poor prognosis. ${ }^{5}$ We present an unusual case of proptosis as the index sign of malignancy and review the literature surrounding orbital and ocular metastases in prostate cancer and renal cell carcinoma (RCC).

\section{Case report}

In January 2006, a highly functional 81-year-old man wth a history of peripheral vascular disease developed proptosis and pain in the left eye, which had been blind for 50 years due to unrelated causes.

Magnetic resonance imaging (MRI) with gadolinium revealed a $2.7-\mathrm{cm}$ homogenously enhancing left orbital mass encasing the optic nerve, extending along the lateral aspect of the globe and displacing it medially (Fig. 1a). Brain imaging was non-contributory. High resolution computed tomography $(\mathrm{CT})$ of the orbits confirmed no bone involvement (Fig. 1b).

With a working diagnosis of melanoma or meningioma, left enucleation and debulking was performed. The orbital mass was centrally cored and decompressed internally, leaving the peripheral margins of the tumour intact. The specimen was a firm white mass extending over the posterior sclera and encasing the optic nerve. The tumour involved the anterior chamber, ciliary body, choroid and sclera, with extension into the episcleral and orbital soft tissues. Immunophenotyping was positive for pankeratin, vimentin, CD20, P504S and prostate-specific antigen (PSA), and negative for CK7, CK20 and prostate specific acid phosphatase (PSAP). RCC and androgen receptor antibodies were not available at that time. The pathologic assessment described a poorly differentiated adenocarcinoma consistent with a prostate primary.

The patient was seen at our institution 2 months later. He reported obstructive urinary symptoms. A firm irregularity of the right prostate was palpable, consistent with $\mathrm{T} 2 \mathrm{~b}$ disease. His PSA was $8.9 \mu \mathrm{g} / \mathrm{L}$. Baseline bone scan showed increased uptake in the left fourth rib, but no bony orbital involvement (Fig. 2). Given the constellation of urinary symptoms, abnormal digital rectal examination (DRE), elevated PSA, pathology and bone scan findings, the patient was started on leuprolide and flutamide for metastatic prostate cancer. He did not have a prostate biopsy.

Two months following the first leuprolide injection, his PSA had declined to $0.6 \mu \mathrm{g} / \mathrm{L}$. The patient's ophthalmologist noted a dramatic improvement with decreased intraorbital pressure and improved cosmesis. Given the degree of local response, further surgical intervention was not necessary and the patient continued with anti-androgen therapy.

The patient did well for about two years, when he developed impending spinal cord compression. His PSA was $0.36 \mu \mathrm{g} / \mathrm{L}$ and a CT identified a $9.6 \times 4.8-\mathrm{cm}$ expansile 


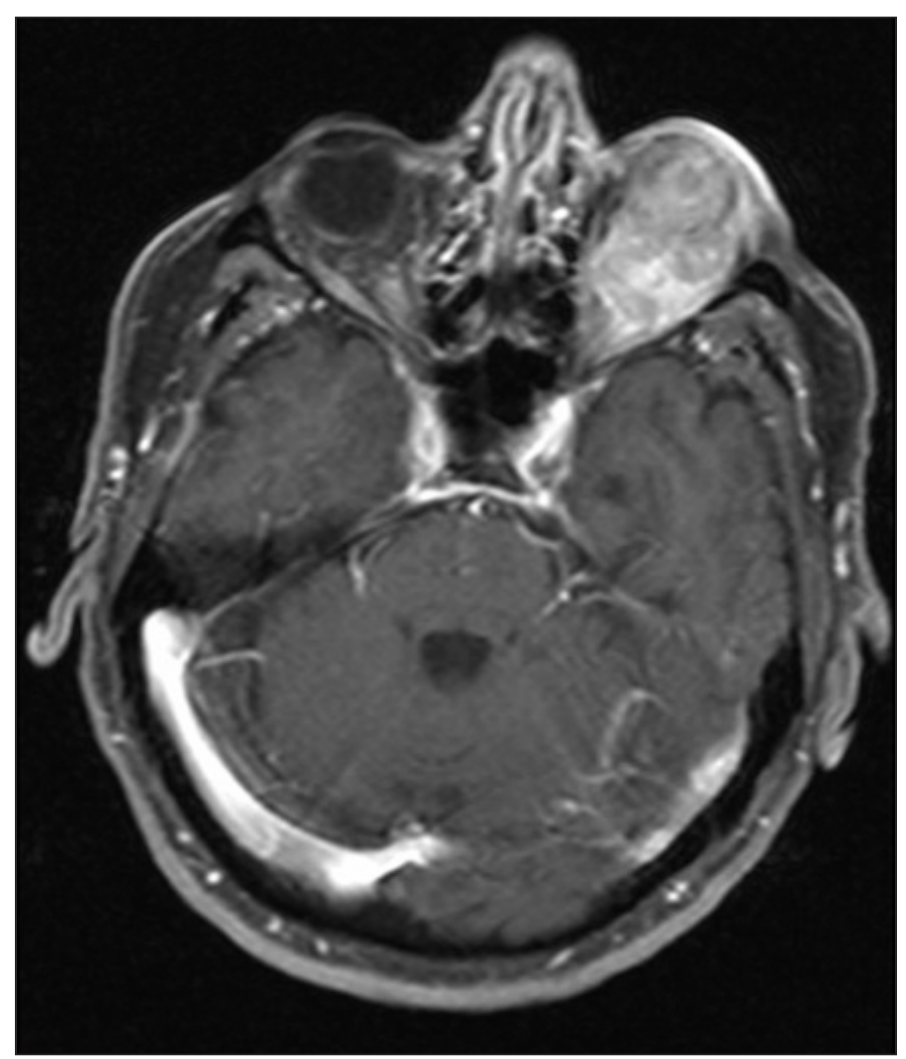

Fig. 1a. Axial T2-weighted magnetic resonance imaging.

lytic lesion involving the left fourth rib and T4 vertebral body with a large soft tissue component. Given this unusual radiologic presentation, a biopsy was performed. The morphologic findings were similar to those of the ocular specimen. Palliative radiotherapy was administered.

Three months later, a CT of the chest, abdomen and pelvis identified progression of the irradiated rib lesion; PSA was $0.3 \mu \mathrm{g} / \mathrm{L}$. The putative radioresistance and low PSA at the time of radiologic progression prompted pathology review. The ocular sample was morphologically consistent with a clear cell neoplasm with acinar and papillary architecture. Immunohistochemistry studies directed at PSA, previously reported as positive, were reviewed as negative, with minimal expression. The prostate acid phospha (PAP) was negative. Additional testing revealed epithelial membrane antigen (EMA) and RCC expression, minimal androgen receptor expression, and no E-Cadherin or CD57 expression. These findings were reported as metastatic poorly differentiated adenocarcinoma with RCC as the most likely primary site. The rib biopsy showed similar histopathologic features.

Abdominal ultrasound and CT identified three renal cysts: a 7-mm cyst within the left kidney and two cysts measuring $1.3 \mathrm{~cm}$ and $2.0 \mathrm{~cm}$ within the right kidney. The lesions were classified as Bosniak II. Review of a CT angiogram and Doppler ultrasound performed 7 months prior as a preoperative assessment for femoral-femoral bypass confirmed

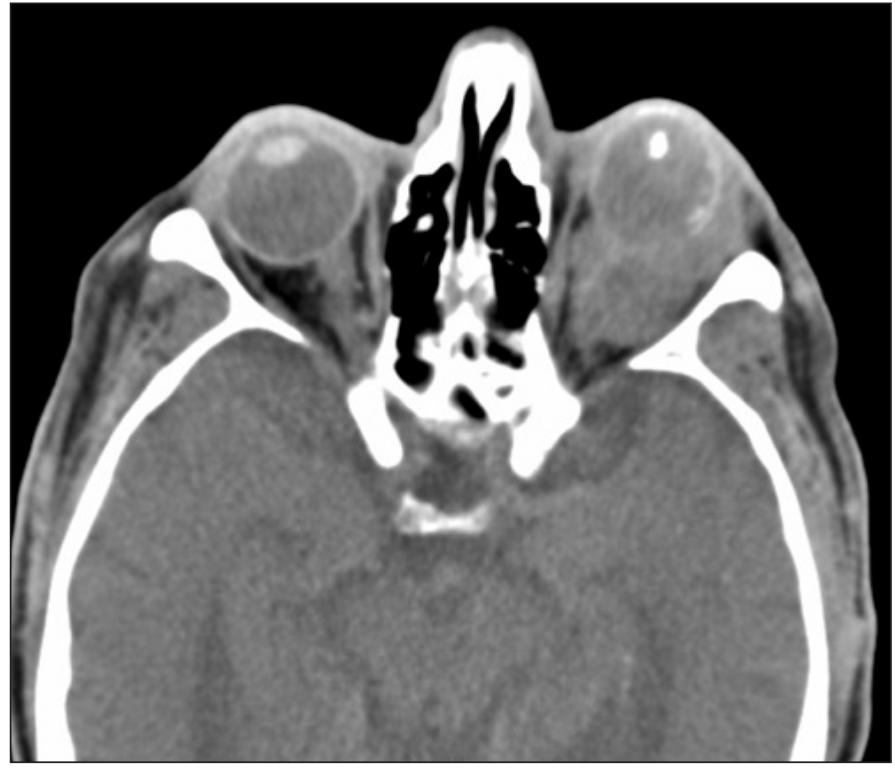

Fig. $\mathbf{1 b}$. High resolution axial computed tomography scan.

that the cysts had been present and were stable in size. Unfortunately, the patient's disease continued to progress; neither confirmatory prostate nor renal biopsy were deemed clinically appropriate. He died in November 2008 and no autopsy was performed.

\section{Discussion}

\section{Epidemiology and pathophysiology}

Metastases to the orbital or ocular region typically develop in the setting of diffuse metastatic disease and occur in $2 \%$ to $5 \%$ of all cancer patients; however, it can be the presenting sign of malignancy in up to $25 \%$ of cases..$^{1,6}$ The prognosis is poor with a median survival of 6 to 9 months. ${ }^{5}$

The most commonly reported primary sites are breast (28\%-59\%), lung ( $8 \%-12 \%)$ and prostate $(3 \%-10 \%))^{1,7}$ Of the 48 published cases of orbital and ocular metastases secondary to prostate cancer since $1975,38 \%$ were initial presentations. ${ }^{7,8-19}$ RCC is a rare cause of intraocular and orbital metastases, accounting for $3 \%$ of metastatic orbital tumours. ${ }^{20,21}$ Shome and colleagues identified 71 cases of intraocular and orbital metastasis from RCC between 1934 and $2004 .{ }^{20}$ We identified an additional 6 cases. ${ }^{22-26}$ Of these 77 cases, $47 \%$ were the primary presentation of malignancy.

Metastases to the eye and orbit typically occur through hematogenous spread via the carotid and ophthalmic artery. Genitourinary cancers may access this route via pre-existing pulmonary metastases or through Batson's plexus. ${ }^{27}$ This valveless venous plexus connects the pelvic veins to the vertebral veins. ${ }^{28}$ Tumour cells within the plexus may access the cranial venous sinuses and, subsequently, the ophthal- 
mic veins via changes in venous pressure. ${ }^{29}$ Prostate cancer cells most frequently metastasize to the orbital bone, while RCC shows a predilection for orbital soft tissue. ${ }^{1,20}$

\section{Clinical presentation and diagnosis}

The clinical presentation of metastases to the orbital region depends on the structures affected. For example, pain, diplopia and decreased visual acuity may be present if the orbital bone, soft tissue or globe is affected, respectively. These symptoms may progress over weeks to months., ${ }^{1,30}$ Examination may reveal proptosis, ptosis, ophthalmoplegia or red eye. Complications include retinal detachment, uveitis, papilledema and secondary glaucoma. ${ }^{1,2,8,29}$

Appropriate investigations require consideration of the patient's clinical status and goals. If the patient has a previously-confirmed cancer diagnosis, it would be reasonable to defer further workup in favour of immediate treatment. However, a primary presentation of malignancy in a relatively healthy individual requires investigation. Ophthalmologic assessment can confirm a clinical suspicion of neoplasm, determine baseline visual acuity and institute measures to prevent sight-threatening complications. ${ }^{15,31}$ Ultrasound can assess lesion location, size and characteristics. CT best delineates bony orbital disease, while MRI describes soft tissue and optic nerve involvement. ${ }^{1,6,8}$

In the search for a primary site, a thorough history, examination and review of past medical records should be performed. Radiologic investigations may suggest a primary or locate other sites of metastases more amenable to biopsy. If a careful systemic workup does not identify a primary, fine needle aspiration of the lesion is recommended which is diagnostic in $90 \%$ of cases. Potential risks include vision loss, bleeding, infection and dissemination of tumour cells. 1,5,31 Alternatively, if the tumour is accessible and wellcircumscribed, excisional biopsy could be considered. ${ }^{2}$

\section{Treatment}

Treatment is aimed at providing local control to preserve vision, cosmesis and comfort. ${ }^{1,29,31}$ Serial observation is appropriate in asymptomatic patients with slow-growing tumours that do not threaten vision. Chemotherapy or hormonal therapy can be used in the setting of widely metastatic disease. If systemic therapy fails, local treatments should be considered. ${ }^{5}$

A variety of local therapies are available including plaque brachytherapy, phototherapy and surgery; however, no randomized trials have been performed. ${ }^{1,5,8,10,32}$ Currently, the mainstay of treatment is palliative external beam radiotherapy, typically 20 to 40 Gy over 1 to 2 weeks. ${ }^{1,5}$ Tumour and symptom response have been demonstrated in $63 \%$ to $83 \%$ of cases; however, half of these studies were performed in

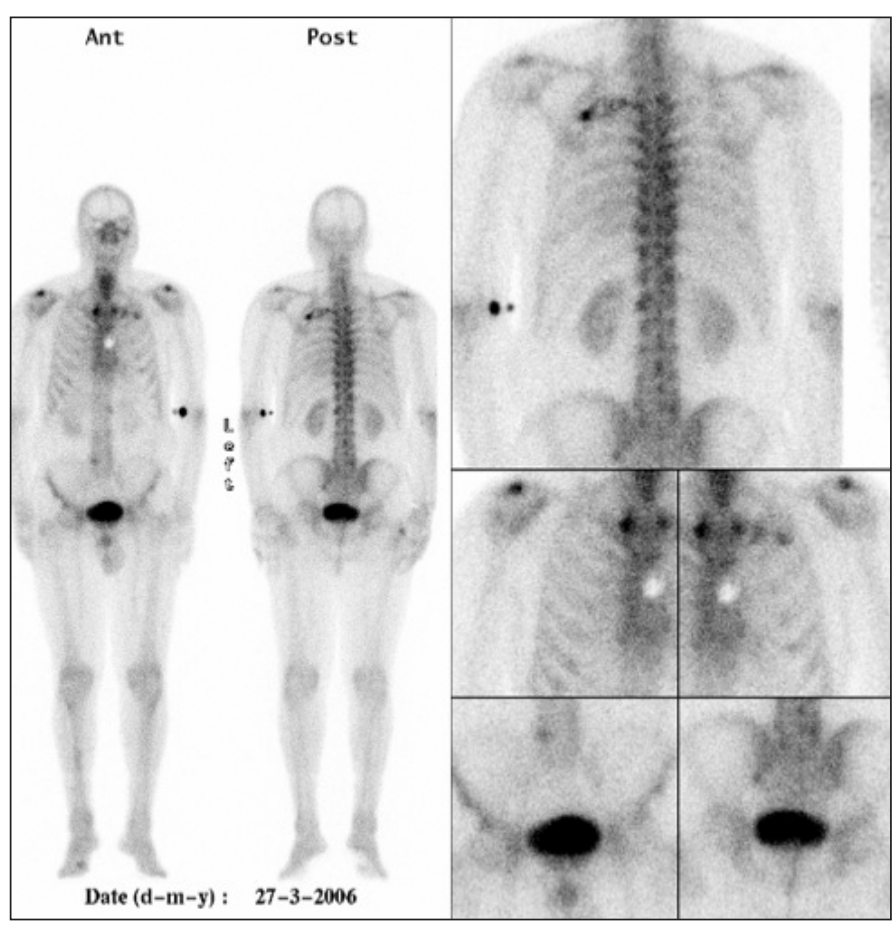

Fig. 2. Baseline bone scan. Findings were significant for increased uptake in the left fourth rib and degenerative changes within the acromia, sternocostal joints and lumbar spine, but negative in the orbit.

breast cancer and the generalizability of these results to other histologies is uncertain. ${ }^{33-38}$ Potential side effects include skin erythema, conjunctivitis, corneal ulceration, cataract formation, retinopathy and neuropathy. ${ }^{1,33,34}$

When response to the above modalities is incomplete, surgical debulking can improve cosmesis and visual acuity. ${ }^{31}$ Enucleation has not been shown to prolong survival and should be reserved for uncontrolled tumour growth, a sightless eye or intractable symptoms. ${ }^{1}$

\section{Our case: A diagnostic dilemma}

We present a puzzling case of an 81-year-old man whose initial presentation of malignancy was proptosis secondary to an orbital tumour. He was originally treated for metastatic prostate cancer; however, due to an unusual clinical course, pathology review was performed and evidence for a RCC metastasis was identified. As with all pathologic information, correlative clinical evidence must be considered.

Our patient's presentation with obstructive urinary symptoms, abnormal DRE, elevated PSA and bone metastases was suggestive of prostate cancer. Although metastatic disease with an initial PSA less than $10 \mu \mathrm{g} / \mathrm{L}$ is uncommon and the positive predictive value of DRE in the setting of elevated PSA is only $46 \%$, the diagnosis of prostate cancer was supported by local tumour response to androgen deprivation therapy. ${ }^{39,40}$ 
Lefresne et al.

RCC, on the other hand, is well-known for its ability to metastasize to unusual locations, has no association with PSA, is relatively radioresistant and has been reported to undergo spontaneous regression. ${ }^{41-43}$ Although three Bosniak II cysts were identified, the difficulty in distinguishing between Bosniak II (benign) and Bosniak III (suspicious

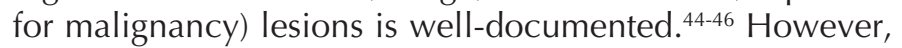
the three-year survival of untreated stage IV RCC is less than $5 \% ;{ }^{47}$ our patient lived for 34 months after his initial diagnosis. Also, spontaneous regression of RCC metastases typically occurs following a nephrectomy. ${ }^{43}$

Interestingly, about $25 \%$ of patients with RCC have multiple primary tumours; prostate cancer is one of the most common concomitant malignancies. ${ }^{48}$ Unfortunately, without tissue samples from the prostate or kidney, the only certain diagnosis is metastatic poorly differentiated adenocarcinoma.

\section{Conclusion}

Metastases to the orbital region are occasionally the primary presentation of cancer and represent a diagnostic challenge. Suspicion of malignancy in this anatomic site requires a rational clinical approach. Referral to an ophthalmologist and thorough investigation if no primary is evident is often warranted. In an older male with visual complaints and urinary symptoms, the genitourinary system should be evaluated as a potential primary site as prostate cancer is one of the main sources of orbital metastases. Although prognosis is generally poor, both local and systemic treatment options exist to address symptoms and preserve visual acuity.

Competing interests: None declared.

This paper has been peer-reviewed.

\section{References}

1. Ahmad SM, Esmaeli B. Metastatic tumors of the orbit and ocular adnexa. Curr Opin Ophthalmol 2007;18:405-13. http://dx.doi.org/10.1097/ICU.0b013e3282c5077c

2. Shields JA, Shields CL, Brotman HK, et al. Cancer metastatic to the orbit: The 2000 Robert M. Curts Lecture. Ophthal Plas Recons Surg 2001;17:346-54. http://dx.doi.org/10.1097/00002341-20010900000009

3. Goldberg RA, Rootman J, Cline R. Tumors metastatic to the orbit: a changing picture. Surv Ophtal 1990;35:1-24. http://dx.doi.org/10.1016/0039-6257(90)90045-W

4. Garrity JA, Henderson JW, Cameron JD. Metastatic carcinomas. In: Henderson's orbital tumors. 4th ed. New York: Raven Press; 2007:313-26.

5. Kanthan GL, Jayamohan J, Yip D, et al. Management of metastatic carcinoma of the uveal tract: an evidence based analysis. Clin Exper Ophthalmol 2007;35:553-65. http://dx.doi.org/10.1111/j.14429071.2007.01550.x

6. Hesselink JR, Davis KR, Weber AL, et al. Radiological evaluation of orbital metastases, with emphasis on computed tomography. Neuroradiol 1980;137:363-6.

7. Autorino R, Zito A, Di Giacomo F, et al. Orbital metastasis as a first indication of prostate cancer: a case report. Arch Ital Urol Androl 2005;77:109-10.
8. Boldt HC, Nerad JA. Orbital metastases from prostate carcinoma. Arch Ophthalmol 1988;106:1403-8. http://dx.doi.org/10.1001/archopht1988.01060140567024

9. Carriere VM, Karcioglu ZA, Apple DJ, et al. A case of prostate carcinoma with bilateral orbital metastases and the review of the literature. Opthalmology 1982;89:402-6.

10. Hill VE, Brownstein $S$, Leonard $B C$, et al. Prostate adenocarcinoma presenting as a solitary choroidal metastasis. Can J Ophthalmol 1998;33:276-9.

11. Isshiki $S$, Cho $S$, Matsuno D, et al. A case of orbital metastasis from prostatic carcinoma as an intial symptom. Hinyokika Kiyo 2007;53:193-5.

12. Khan AU, Greene LF, Neault RW. Orbital metastasis from prostatic carcinoma. Internat Surg 1977; 62:4657.

13. Di Leo A, Bajetta E. Adenocarcinoma of unknown primary site with bone marrow and orbital metastases suggestive of a prostatic origin. Tumori 1992; 78:63-4.

14. Reifler DM, Kini SR, Liu D, et al. Orbital metastasis from prostatic carcinoma: identification by immunocytology. Arch Ophthalmol 1984;102:292-5. http://dx.doi.org/10.1001/archopht.1984.01040030236033

15. Shittu $O B$, Ogunbiyi JO. Orbital metastases of prostatic carcinoma in a tropical African population. WAJM 2003;22:173-6.

16. Tertazkian GM, Herr HW, Mehta MB. Orbital metastases from prostatic carcinoma. Urology 1982;19:4279. http://dx.doi.org/10.1016/0090-4295(82)90205-9

17. Uluocak N, Parlaktas BS, Deniz FE, et al. Orbital metastasis of prostate cancer: a case report. Kaohsiung J Med Sci 2007;23:199-202. httr://dx.doi.org/10.1016/S1607-551X(09)70398-5

18. Usui T, Ishibe T, Nihira H. Orbital Metastasis from prostatic carcinoma. Br J Urol 1975;475:458. http:// dx.doi.org/10.1111/i.1464-410X.1975.tb04007.x

19. Winkler CF, Goodman GK, Eiferman RA, et al. Orbital metastasis from prostatic carcinoma: identification by an immunoperoxidase technique. Arch Ophthalmol 1981;99:1406-8. http://dx.doi.org/10.1001/ archopht.1981.03930020280016

20. Shome D, Honavar SG, Gupta P, et al. Metastasis to the eye and orbit from renal cell carcinoma - a report of three cases and review of the literature. Surv Ophthalmol 2007;52:213-23. http://dx.doi. org/10.1016/.isurvophthal.2006.12.004

21. Rootman J. Diseases of the orbit. 2nd ed. Philadelphia, PA: Lippincott Williams and Wilkins; 2003.

22. Hart RH, Luthert PJ, Rose GE. Renal cell carcinoma metastasis masquerading as recurrent orbital hematoma. Orbit 2005;24:281-4. http://dx.doi.org/10.1080/01676830500263794

23. Mancini $V$, Battaglia $M$, Lucarelli $G$, et al. Unusual solitary metastasis of the ciliary body in renal cell carcinoma. Internat J Urol 2008;15:363-5. htrp://dx.doi.org/10.1111/j.1442-2042.2008.02004.x

24. Pompeu ACL, Arap S, Silva MNR, et al. Ocular metastasis as first presentation of renal cell carcinoma: report of 2 cases. Clinics 2005;60:75-8. http://dx.doi.org/10.1590/S1807-59322005000100014

25. Preechawai P, Amrith S, Yip CC, et al. Orbital metastasis of renal cell carcinoma masquerading as cysticercosis. Orbit 2008;27:370-3. http://dx.doi.org/10.1080/01676830802316688

26. Vozmediano-Serrano MT, Toledano-Fernandez N, Fdez-Acenero MJ, et al. Lacrimal sac metastases from renal cell carcinoma. Orbit 2006;25:249-51. http://dx.doi.org/10.1080/01676830600575550

27. Ferry AP, Font RL. Carcinoma metastatic to the eye and orbit. Arch Ophthalmol 1974;92:276-86. http:// dx.doi.org/10.1001/archopht.1974.01010010286003

28. Arya M, Bott SR, Shergill IS, et al. The metastatic cascade in prostate cancer. Surg Onc 2006;15:117-28. http://dx.doi.org/10.1016/i.suronc.2006.10.002

29. Baltogiannis D, Kalogeropoulos C, loachim E, et al. Orbital metastasis from prostatic carcinoma. Urol Int 2003;70:219-22. http://dx.doi.org/10.1159/000068753

30. Vissamsetti B, Mcardle PA, Adam CJ, et al. Proptosis - an uncommon presentation of orbital metastases secondary to prostate cancer. Urol Int 2007;79:374-5. http://dx.doi.org/10.1159/000109728

31. Char DH, Miller T, Kroll S. Orbital metastases: diagnosis and course. Br J Ophthal 1997;81:386-90. http://dx.doi.org/10.1136/bjo.81.5.386

32. Hingorani $M$, Davies $A$, Nischal $K$, et al. Prostatic orbital metastases and the role of the ophthalmologist. Br J Urol 1996;78:642-58.

33. Rudoler S, Corn B, Shields C, et al. External beam irradiation for choroid metastases: identification of factors predisposing to long term sequelae. Int I Radiat Oncol Biol Phys 1997;38:251-6. hittp://dx.doi. org/10.1016/50360-3016(97)00050-3

34. Rosset A, Zografos L, Coucke P, et al. Radiotherapy of choroidal metastases. Radiother Oncol 1998;46:2638. http://dx.doi.org/10.1016/S0167-8140(97)00209-0

35. Wiegel T, Bottke D, Kreusel K, et al. External beam radiotherapy of choroidal metastases - final results of a prospective study of the German Cancer Society (ARO 95-08). Radiother Oncol 2002;64:13-8. http://dx.doi.org/10.1016/S0167-8140(02)00134-2

36. Demirci H, Shields C, Chao A, et al. Uveal metastasis from breast cancer in 264 patients. Am I Ophthalmol 2003;136:264-71. htrp://dx.doi.org/10.1016/S0002-9394(03)00192-2

37. Thatcher $\mathrm{N}$, Thomas PR. Choroidal metastases from breast carcinoma: a survey of 42 patients and the use of radiation therapy. Clin Radiol 1975;26:549-53. http://dx.doi.org/10.1016/S00099260(75) $80120-6$ 
Ocular metastases and the GU system

38. Chu F, Huh S, Nisce L, et al. Radiation therapy of choroidal metastases from breast cancer. Int J Radiat Oncol Biol Phys 1977;2:273-9. http://dx.doi.org/10.1016/0360-3016(77)90085-2

39. Catalona WJ, Smith DS, Ratliff TL, et al. Measurement of prostate-specific antigen in serum as a screening test for prostate cancer. N Engl J Med 1991;25:1156-61. http://dx.doi.org/10.1056/ NEJM199104253241702

40. Brawer MK, Chetner MP, Beatie J, et al. Screening for prostatic carcinoma with prostate specific antigen. J Urol 1992;147:841-5

41. Ritchie A, Chisholm G. The natural history of renal carcinoma. Semin Oncol 1983;10:390-400.

42. Motzer R, Bander N, Nanus D. Renal-cell carcinoma. N Engl J Med 1996;335:865-75. http://dx.doi. org/10.1056/NEJM199609193351207

43. Hammad AM, Gianmarco RP, van Heuven WAJ, et al. Spontaneous regression of choroidal metastasis from renal cell carcinoma. Am J Ophthalmol 2003;135:911-3. http://dx.doi.org/10.1016/500029394(02)01973-6

44. Curry NS, Cochran ST, Bissada NK. Cystic renal masses accurate bosniak classification requires adequate renal CT. AJR Am J Roentgenol 2000;175:339-42.
45. Aronson S, Frazier HA, Baluch JD, et al. Cystic renal masses: usefulness of the Bosniak classification. Urol Radiol 1991;13:83-90. http://dx.doi.org/10.1007/BF02924596

46. Benejam-Gual JM, Diez-Caballero AF, García-Miralles GR. Complex renal cyst. Laparoscopic treatment. Urol Esp 2006;30:626-9.

47. Figlin R. Renal cell carcinoma: management of advanced disease. J Urol 1999;161:381-7. hittp://dx.doi. org/10.1016/S0022-5347(01)61897-4

48. Rabbani F, Reuter VE, Katz J, et al. Second primary malignancies associated with renal cell carcinoma: influence of histologic type. Urology 2000;56:399-403. http://dx.doi.org/10.1016/S0090$4295(00) 00682-8$

Correspondence: Dr. Alysa Fairchild, Department of Radiation Oncology, Cross Cancer Institute, 11560 University Ave., Edmonton, AB T6G 1Z2; fax: 780-432-8380 ; alysa@ualberta.ca 